\title{
Idiopathic Hemochromatosis with the Mutation of Ala176Val Heterozygous for HFE Gene
}

\author{
Hiroyasu Imanishi, Weidong LiU*, Jidong Cheng**, Naoto IkedA, Yoshiki Amuro and Toshikazu HadA
}

\begin{abstract}
Most patients with hereditary hemochromatosis are homozygous for C282Y in the HFE gene in populations of Celtic origin, but the genetic cause of this disease is unknown in Japan because of its rarity. A 48-year-old Japanese patient was recently diagnosed with idiopathic hemochromatosis. Analysis of the entire coding region of the patient's HFE by RT-PCR showed a heterozygous nucleotide substitution at nucleotide 527 from $C$ to $T$, which resulted in A176V amino acid substitution. Another mutation at nucleotide 942 from $T$ to $C$ was observed, but this was a nonsense mutation. $\mathrm{C282Y}$ and another mutation, H63D, were not found in the patient. The mutation may have a possible role on the cause of hemochromatosis in this Japanese case.

(Internal Medicine 40: 479-483, 2001)
\end{abstract}

Key words: C282Y, RT-PCR, point mutation

\section{Introduction}

Hemochromatosis is characterized by inappropriately high iron absorption that leads to iron overload of many organs. Hereditary hemochromatosis is one of the most common inherited diseases in the northern Europe population with a Celtic origin with a prevalence of approximately 1:300 and a carrier rate of $1: 12$.

In 1996 the gene hereditary hemochromatosis (HFE) was identified (1). Two mutations, Cys282 to Tyr: C282Y (G to A at nucleotide 845) and His63 to Asp: H63D (C to G at nucleotide 187) have been described in this gene. Especially, many studies confirmed that the $\mathrm{C} 282 \mathrm{Y}$ substitution was the main mutation in the development of hereditary hemochromatosis (2-4). However, hereditary hemochromatosis can occur in adults who do not have $\mathrm{C} 282 \mathrm{Y}$ or H63D mutations. The $\mathrm{C} 282 \mathrm{Y}$ substitution is absent in Asian people $(5,6)$ including Japanese
(7). Actually more than $10 \%$ of European and Asian patients with hemochromatosis do not have the mutations (8-10). These findings suggest that Japanese hemochromatosis has the possibility of other mutations which have not yet been reported in the HFE gene. Recently, a Japanese man suffering from idiopathic hemochromatosis was found and treated by venesection at regular intervals, and the entire coding region of the patient's HFE gene was analyzed.

\section{Case Report}

\section{Patient}

A 48-year-old Japanese man was referred to our hospital because of liver dysfunction. There was no history of alcohol abuse, transfusions or excessive iron intake. There was no known family history of hereditary hemochromatosis or hereditary anemia. Physical examination showed mild hepatomegaly and gray-slaty pigmentation of the skin. There were no ascites or hepatic encephalopathy. Liver function tests (Table 1) revealed a mild elevation of aspartate aminotransferase 80 $\mathrm{IU} / l$, alanine aminotransferase $96 \mathrm{IU} / l$ and alkaline phosphatase 3.5 BLU. Total bilirubin was $0.8 \mathrm{mg} / \mathrm{dl}$, albumin $3.8 \mathrm{~g} / \mathrm{dl}$ and prothrombin time $69 \%$. The patient had elevated serum iron $151 \mu \mathrm{g} / \mathrm{dl}$ (normal: $80-150$ ), serum ferritin $6,487 \mathrm{ng} / \mathrm{ml}$ (normal: 29-181) and transferrin saturation $86 \%$ (normal: $20-45$; transferrin saturation was calculated by dividing the serum iron concentration by the total serum iron-binding capacity). Results of serological tests for hepatitis B and C were negative. An oral glucose tolerance test showed a diabetic pattern. Computed tomographic scans of the abdomen showed increased hepatic CT density (Fig. 1A). A liver biopsy was performed for diagnostic purposes and staging of his disease. The liver biopsy specimen was prepared with hematoxylin/eosin and berline blue staining. Histological examination of the liver biopsy specimen showed cirrhosis with massive hepatocellular siderosis: grade 3 (according to the classification of Scheuer) (11) as well as iron in bile duct cells and macrophages (Fig. 2).

The patient has been treated with phlebotomy of $300 \mathrm{ml}$ of blood twice a month for approximately 2 years. Hepatic CT

From the Third Department of Internal Medicine, Hyogo College of Medicine, Nishinomiya and *the Department of Infectious Disease and **Tumor Institute, Shantou University Medical College, Shantou, Guangdong 515031, China

Received for publication May1, 2000; Accepted for publication October 27, 2000

Reprint requests should be addressed to Dr. Toshikazu Hada, the Third Department of Internal Medicine, Hyogo College of Medicine, 1-1 Mukogawa, Nishinomiya, Hyogo 663-8501 
Table 1. Laboratory Data on Admission

\begin{tabular}{lr}
\hline Hematology & \\
Red blood cells & $395 \times 10^{4} / \mu \mathrm{l}$ \\
Hemoglobin & $12.1 \mathrm{~g} / \mathrm{dl}$ \\
Hematocrit & $36.2 \%$ \\
Platelets & $13.4 \times 10^{4} / \mu \mathrm{l}$ \\
White blood cells & $5,500 / \mu \mathrm{l}$ \\
Prothrombin time & $69 \%$ \\
& \\
Blood chemistry & \\
Total protein & $7.2 \mathrm{~g} / \mathrm{dl}$ \\
Albumin & $3.8 \mathrm{~g} / \mathrm{dl}$ \\
Total bilirubin & $0.8 \mathrm{mg} / \mathrm{dl}$ \\
Direct bilirubin & $0.2 \mathrm{mg} / \mathrm{dl}$ \\
Aspartate aminotransferase & $80 \mathrm{IU} / l$ \\
Alanine aminotransferase & $96 \mathrm{IU} / l$ \\
Alkaline phosphatase & $3.5 \mathrm{BLU}$ \\
$\gamma$-glutamyltranspeptidase & $30 \mathrm{IU} / l$ \\
& \\
Ferritin & $6,487 \mathrm{ng} / \mathrm{ml}$ \\
TIBC & $174 \mu \mathrm{g} / \mathrm{dl}$ \\
UIBC & $26 \mu \mathrm{g} / \mathrm{dl}$ \\
Serum iron & $151 \mu \mathrm{g} / \mathrm{dl}$ \\
Transferrin saturation & $86 \%$ \\
& \\
Virus markers & \\
Hepatitis B surface antigen & $(-)$ \\
Anti-hepatitis B surface antibody & $(+)$ \\
Anti-hepatitis C virus antibody & \\
Tumor marker & \\
$\alpha$-fetoprotein & \\
\hline & \\
\hline
\end{tabular}

TIBC: total serum iron-binding capacity, UIBC: unsaturated serum iron-binding capacity. density (Fig. 1B) and iron status improved after the treatment (ferritin: $6,487 \mathrm{ng} / \mathrm{ml}$ to $877 \mathrm{ng} / \mathrm{ml}$; transferrin saturation: $86 \%$ to $60 \%$ ).

\section{Methods}

Informed consent was obtained before taking the blood sample for HFE analysis.

The total RNA of the patient's peripheral white blood cells was extracted using an IsoQuick nucleic acid extraction kit (ORCA Research, Bothell, WA, USA). Then mRNA was purified from the total RNA using Oligotex-dT30<super> (Takara, Otsu, Japan). Nested RT-PCR was performed with newly designed primers which covered the entire coding region of the HFE gene using a RNA PCR kit (AMV) Ver 2.1 (Takara, Otsu, Japan) (Fig. 3). The DNA sequences of the PCR primers were F1 (forward, external): 5'-AGCGGAGATTTAACGGGGACGT-3'; R1 (reverse, external): $5^{\prime}$-TTGTCTCCTTCCCACAGTGA-3'; F1a (=F1, forward, internal): $5^{\prime}$-AGCGGAGATTTAACGGGGACGT-3'; R1a (reverse, internal): $5^{\prime}$-ACTTGTTGGTCCAAAACACCTCT-3'; F1b (forward, internal): 5'-AGCTGAGTCAGAGTCTGA-3'; R1b (reverse, internal): 5'-TAGTTCAAGGCCCGACACCG-3'; F1c (forward, internal): 5'-AACCACAGCAAGGAGTCCCACA-3'; R1c (reverse, internal): 5'-ACTCCAATGACTAGGGTGCCAG-3'; F2 (=F1b, forward, external): 5'-AGCTGAGTCAGAGTCTGA-3'; R2 (reverse, external): 5'-GAGAGGTCACAGCTAGGGATCA-3'; F2a (forward, internal): $5^{\prime}$-GCCTCCTTTGGTGAAGGTGACA-3'; R2a (=R1c, reverse, internal): 5'-ACTCCAATGACTAGGGTGCCAG$3^{\prime}$; F2b (forward, internal): 5'-GAGCAGAGATATACGTGCCAGG$3^{\prime} ; \mathrm{R} 2 \mathrm{~b}$ (=R1, reverse, internal): 5'-TTGTCTCCTTCCCACAGTGA$3^{\prime} ;$ F2c (forward, internal): 5'-ATGGGGCACTACGTCTTAG-3' and R2c (=R2, reverse, internal): 5'-GAGAGGTCACAGCTAGGGATCA-3'.

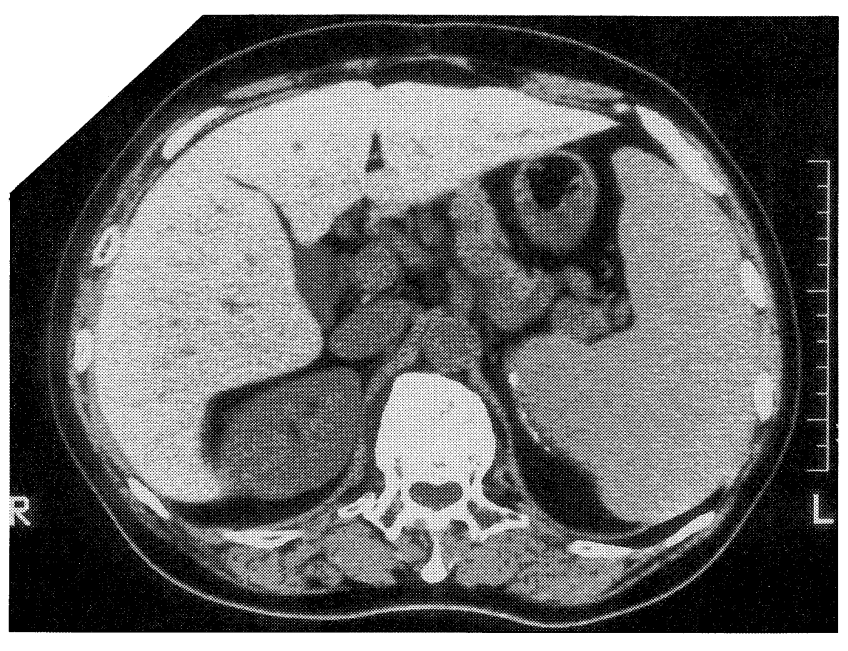

A

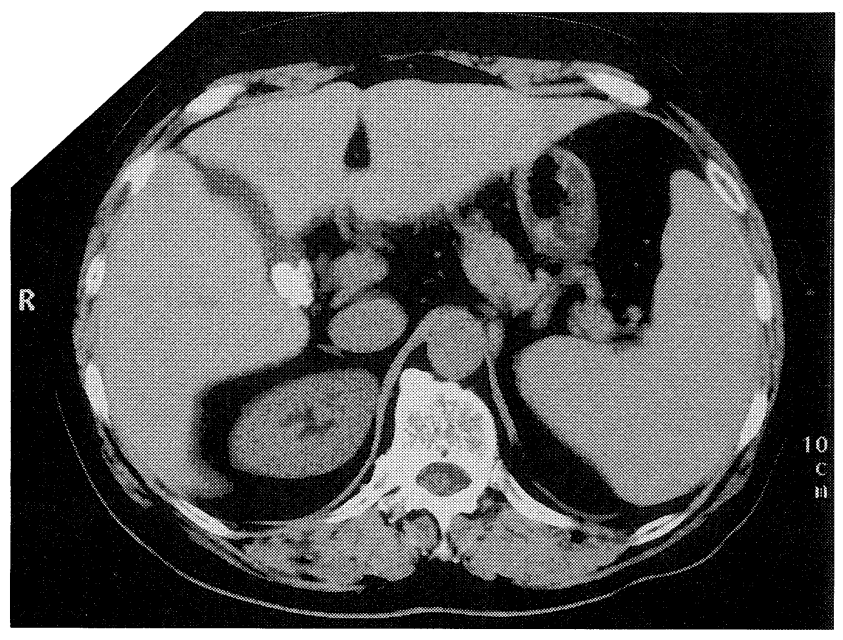

B

Figure 1. Abdominal CT shows increased hepatic CT density which was decreased after repeated phlebotomy. (A) before treatment; (B) after treatment. 


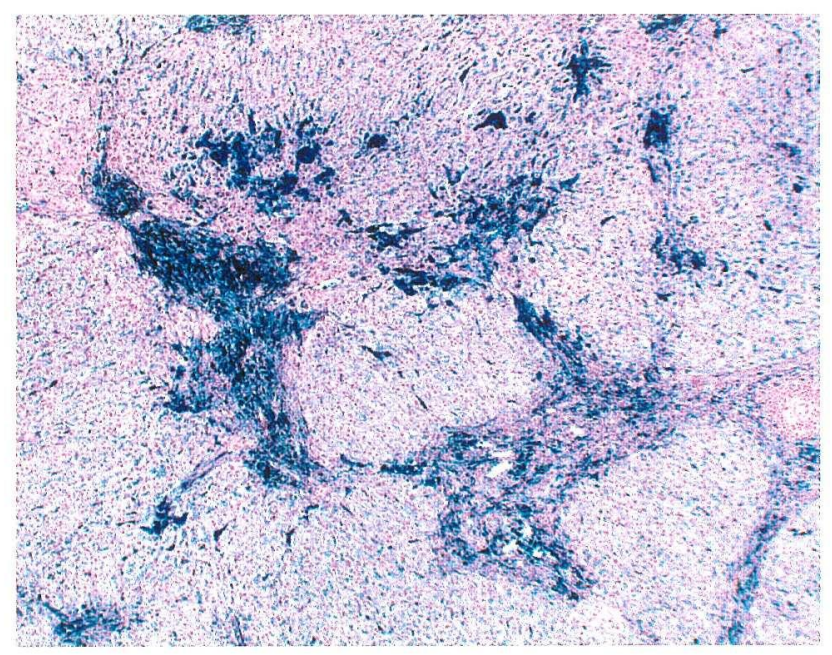

A

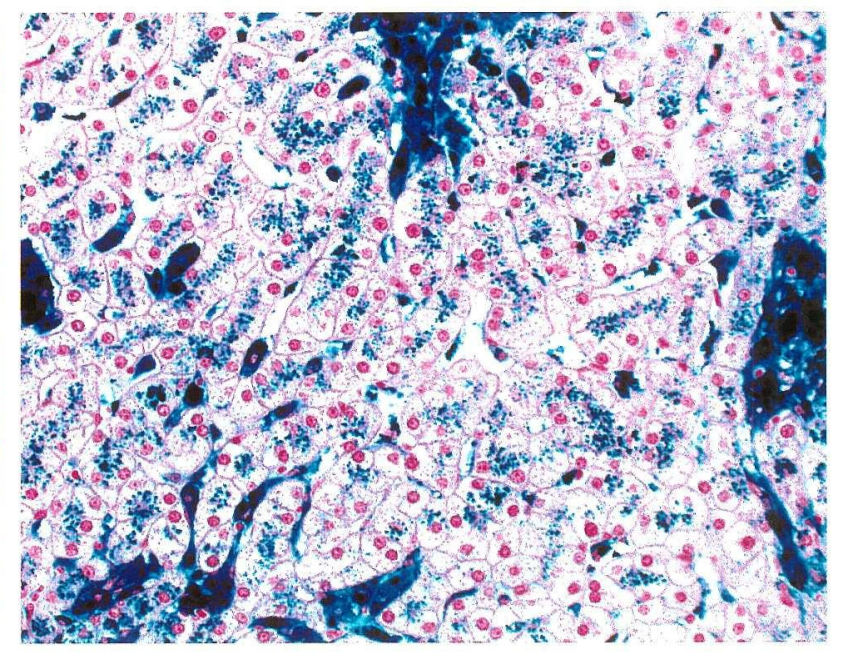

$\mathrm{B}$

Figure 2. Berlin blue stain of the liver. The liver specimen shows cirrhosis. Iron deposits in the hepatocytes (grade 3), macrophages and bile ducts $(\mathrm{A}: \times 40, \mathrm{~B}: \times 100)$.

ORF

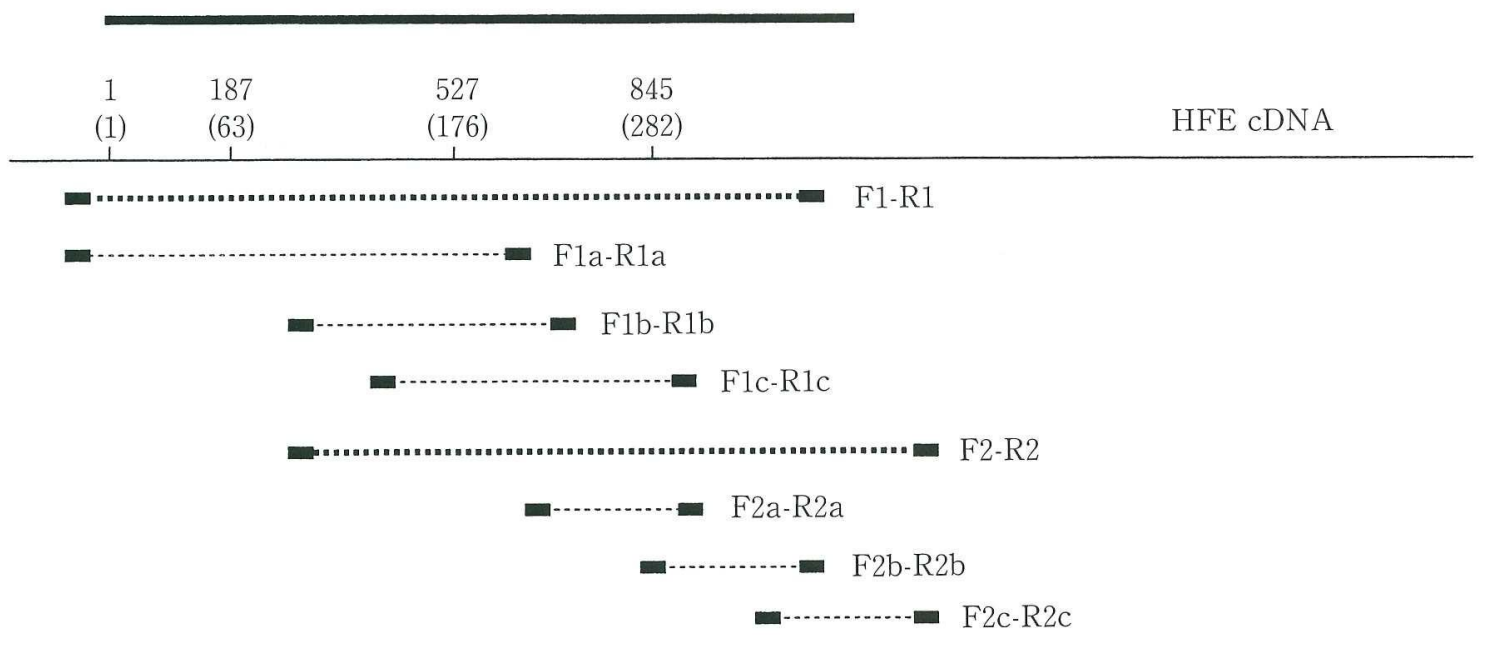

Figure 3. Strategy for nested RT-PCR. Bold dotted lines indicate PCR products produced by external primers. Other dotted lines indicate PCR products produced by internal primers. We use the numbering system which begins at initial methionine: nucleotide number (amino acid number).

After confirming the sizes and homogenity of the PCR products by agarose gel electrophoresis, direct sequencing of the entire coding region of the patient's HFE gene was performed using PCR primers and a Dye terminator cycle sequencing core kit (Perkin-Elmer, Branchburg, NJ, USA) and ABI 373 DNA sequencer. Sequences were determined for both sense and antisense strands. The data were analyzed using DNASIS-MAC v3.6. Blood samples from four volunteers were also used as normal controls after informed consent.

\section{Results}

Two point mutations were observed in comparison with the sequence of the reported HFE gene (GenBank accession number U60319) (Fig. 4). The first point mutation was $\mathrm{C}$ to $\mathrm{T}$ transition at nucleotide 527 resulting in the substitution of valine for alanine at amino acid 176. [We used the numbering system which began at initial methionine.] This Ala176Val (A176V) mutation was a heterozygote.

The second mutation, a homozygous mutation, was $\mathrm{T}$ to $\mathrm{C}$ transition at nucleotide 942 , but this mutation did not result in 
IMANISHI et al
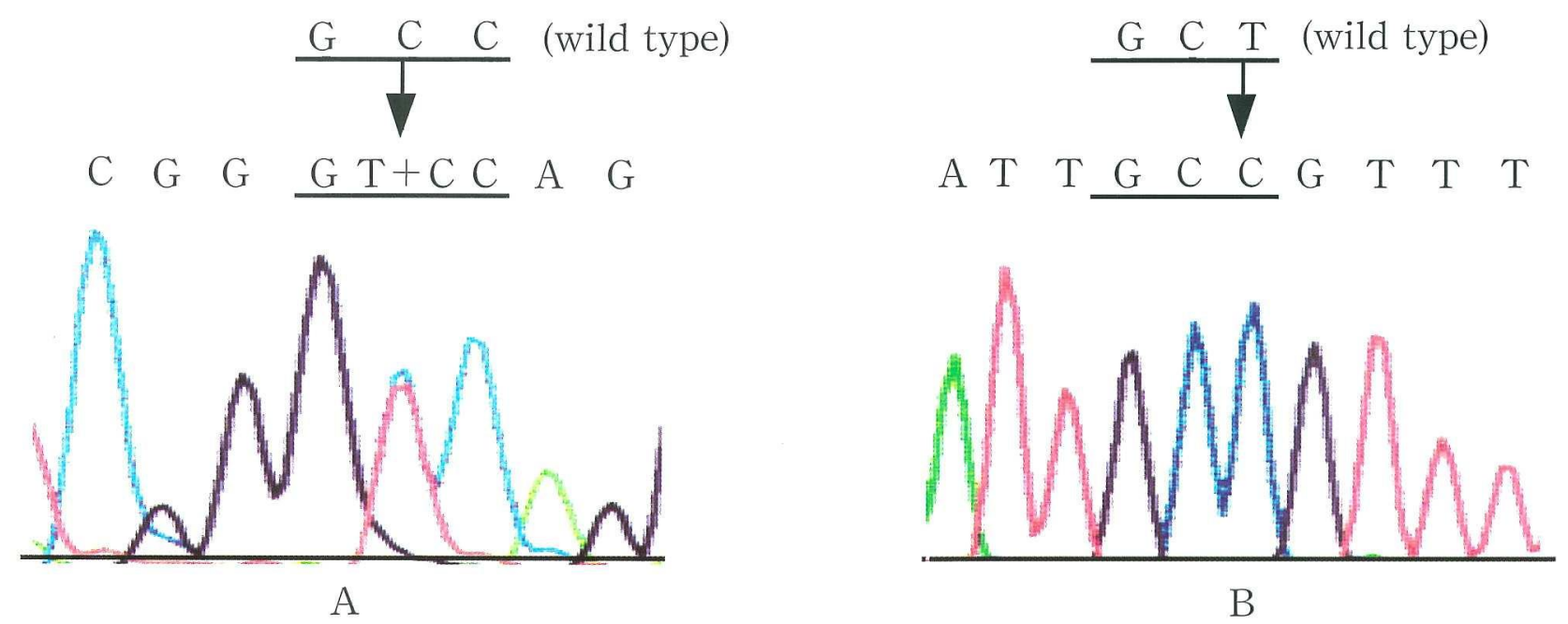

Figure 4. A) DNA sequence from the patient representing heterozygous mutation at nucleotide $527 \mathrm{C} \rightarrow \mathrm{C}+\mathrm{T}$. B) DNA sequence from the patient representing homozygous mutation at nucleotide $942 \mathrm{~T} \rightarrow \mathrm{C}$.

amino acid change. Normal control subjects did not have any nucleotide change in the HFE gene. The C282Y and H63D mutations were not observed in the patient's HFE.

\section{Discussion}

Most patients with hereditary hemochromatosis are homozygous mutation (C282Y/C282Y) or compound heterozygous mutation (C282Y/H63D) of the HFE gene in populations of northern European origin. However, more than 10\% of European patients with hemochromatosis and most Asian patients with this disease do not have the C282Y mutation. The possibility of a new mutation in the HFE gene has been raised to explain the disease without $\mathrm{C} 282 \mathrm{Y}$ mutation.

Here, we report heterozygous A176V mutation in a Japanese patient with idiopathic hemochromatosis. The first discussion point is that the mutation may represent only a polymorphic variant. Several studies for systemic sequencing of the HFE gene showed several mutations of the HFE gene in addition to C282Y and H63D $(12,13)$. These are predominantly localized in intron sequences except for Ser65Cys (S65C) in exon 2. Although $\mathrm{S} 65 \mathrm{C}$ is initially thought to represent only a polymorphic variant, Mura et al (14) suggested that S65C substitution is associated with the mild form of hemochromatosis. [S65C mutation was not found in our patient.] Therefore, we suspect that $\mathrm{A} 176 \mathrm{~V}$ substitution could be a contributing factor to iron overload in hemochromatosis patients like S65C.

The second point is that the $\mathrm{A} 176 \mathrm{~V}$ is heterozygous in our patient. As for the $\mathrm{C} 282 \mathrm{Y}$ mutation, serum markers of iron status (ferritin and transferrin saturation) were shown to be higher in people heterozygous for $\mathrm{C} 282 \mathrm{Y}$ than in people homozygous for wild type (15). However, the levels of serum ferritin and transferrin saturation were not as high as those in people ho- mozygous for $\mathrm{C} 282 \mathrm{Y}$. The mutation found in our patient was heterozygous for the HFE gene, but the levels of serum markers of iron status were as high as those of the patients whose mutation is homozygous for $\mathrm{C} 282 \mathrm{Y}$. It is unclear whether the A176V heterozygous mutation contributed to iron overload. Although a heterozygote of A176V substitution may possibly increase the risk of developing hemochromatosis, a genetic mutation other than the HFE gene must be studied in order to clarify the meaning of A176V mutation. The present case may present only a private mutation. However, it is worth reporting because of the rarity of idiopathic hemochromatosis in Japan. This is the first report of a Japanese patient with idiopathic hemochromatosis whose entire coding region of the HFE gene was analyzed.

\section{References}

1) Feder JN, Gnirke A, Thomas W, et al. A novel MHC class I-like gene is mutated in patients with hereditary haemochromatosis. Nat Genet $\mathbf{1 3}$ 399-408, 1996.

2) Jazwiska EC, Cullen LM, Busfield F, et al. Haemochromatosis and HI.AH. Nat Genet 14: 249-251, 1996.

3) Jouanolle AM, Gandon G, Jézéquel P, et al. Haemochromatosis and HLAH. Nat Genet 14: 251-252, 1996.

4) Brissot P, Moirand R, Jouanolle AM, et al. A genotypic study of 217 unrelated probands diagnosed as "genetic hemochromatosis" on "classical" phenotypic criteria. J Hepatol 30: 588-593, 1999.

5) Merryweather-Clarke AT, Pointon JJ, Shearman JD, Robson KJH. Global prevalence of putative haemochromatosis mutations. J Med Genet 34: 275-278, 1997.

6) Oliver M, Scully L, Guiraudon C, Adams PC. Non-HLA-linked hemochromatosis in a chinese woman. Dig Dis Sci 40: 1589-1591, 1995.

7) Sohda T, Yanai J, Soejima H, Tamura K. Frequencies in the Japanese population of HFE gene mutations. Biochemical Genet 37: 63-68, 1999.

8) Piperno A, Sampietro M, Pietrangelo A, et al. Heterogenity of hemochromatosis on Italy. Gastroenterology 114: 996-1002, 1998.

9) Carella MD, Ambrosio L, Totaro A, et al. Mutation analysis of the HLA- 


\section{Hemochromatosis with a HFE Mutation}

$\mathrm{H}$ gene in Italian hemochromatosis patients. Am J Hum Genet 60: 828832, 1997.

10) Hattori K, Hayashi H, Takikawa T, et al. No HLA-H mutation (845G to A) in Japanese patients with hemochromatosis. Hepatology 26: 522A, 1997.

11) Scheuer PJ, Williams R, Muir AR. Hepatic pathology in relatives of patients with hemochromatosis. J Path Bact 84: 53-64, 1962.

12) Beutler $E$, West $C$, Gelbart T. HLA-H and associated proteins in patients with hemochromatosis. Mol Med 3: 397-402, 1997.
13) Douabin V, Moirand R, Jouanolle AM, et al. Polymorphisms in HFE gene. Hum Hered 49: 21-26, 1999.

14) Mura $C$, Raguenes $O$, Ferec C. HFE mutations analysis in 711 hemochromatosis probands: Evidence for $\mathrm{S} 65 \mathrm{C}$ implication in mild form of hemochromatosis. Blood 93: 2502-2505, 1999.

15) Bulaj ZJ, Griffen LM, Jorde LB, Edwards CQ, Kushner JP. Clinical and biochemical abnormalities in people heterozygous for hemochromatosis. N Eng J Med 335: 1799-1805, 1966. 